\title{
Tuning the Porosity of Supraparticles
}

\author{
Wendong Liu, ${ }^{(0)}$ Michael Kappl,*() and Hans-Jürgen Butt ${ }^{(0)}$ \\ Department of Physics at Interfaces, Max Planck Institute for Polymer Research, Ackermannweg 10, D-55128 Mainz, Germany
}

\section{Supporting Information}

\begin{abstract}
Supraparticles consisting of nano- or microparticles have potential applications as, for example, photonic crystals, drug carriers, or heterogeneous catalysts. To avoid the use of solvent or processing liquid, one can make supraparticles by evaporating droplets of aqueous suspensions from super-liquid-repellent surfaces. Herein, a method to adjust the porosity of supraparticles is described; a high porosity is desired, for example, in catalysis. To prepare highly porous $\mathrm{TiO}_{2}$ supraparticles, polymer nanoparticles are co-dispersed in the suspension. Supraparticles are formed through evaporation of aqueous suspension droplets on superamphiphobic surfaces followed by calcination of the sacrificial polymer particles. The increase of porosity of up to $92 \%$ resulted in enhanced photocatalytic activity while maintaining sufficient mechanical stability.
\end{abstract}

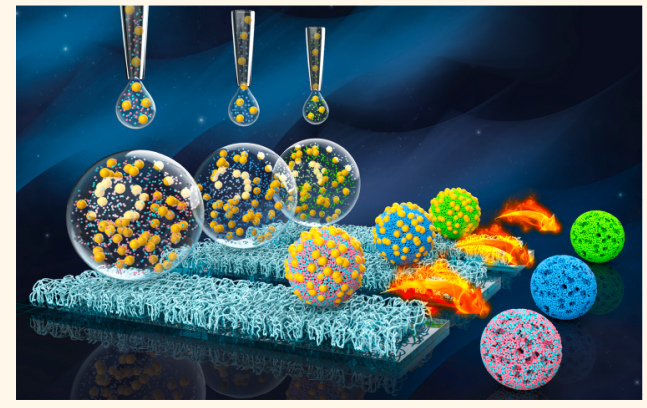

KEYWORDS: supraparticles, porous, evaporation, superamphiphobic surface, photocatalysis

S upraparticles are agglomerates of primary nano- or microparticles with a typical size from a few $10 \mu \mathrm{m}$ to several $100 \mu \mathrm{m}$. For simplicity, we call the all primary particles nanoparticles in the following. As agglomerates, supraparticles assemble nanoparticles into larger entities, making handling and recovery easier, while reducing the hazards associated with the high mobility of the primary nanoparticles. ${ }^{1}$ As an entity, such a superstructure can combine functionalities of the nanoparticles, e.g., high specific surface area, intrinsic material property, catalytic activity. Moreover, supraparticles may exhibit improved functions due to the synergism, coupling, and colocalization, which exceed the performance of simple sum function of primary building blocks. ${ }^{2}$ Therefore, supraparticles have attracted considerable attention and shown specific structure and potential applications, ${ }^{3,4}$ such as absorber materials in chromatography, for heterogeneous catalysis, ${ }^{5}$ for making photonic crystals, ${ }^{6}$ drug carriers, ${ }^{7}$ or energy production and storage materials. ${ }^{8,9}$

A variety of fabrication methods has been developed. Most of the supraparticles are prepared in solution, ${ }^{10}$ e.g., by kinetics/thermodynamics-controlled growth or template-based synthesis. For kinetics/thermodynamics-controlled growth methods, the self-assembly of nanoparticles is triggered by weak interactions such as hydrogen bonding, solvophobic interactions, and dipole-dipole interactions. ${ }^{11-16}$ Instead, in template-based synthesis the assembly is controlled by using a template such as emulsions, mini-emulsions, block copolymer structures, or droplets prepared through microfluidics. ${ }^{17-20}$ While being suitable for large-scale production, these approaches depend on chemicals, especially for size and composition engineering, which need to be separated from the supraparticles and disposed of afterward. These chemicals may harm the environment and their use consumes energy. Therefore, developing simple strategies to reduce or completely avoid the use of solvent, emulsifiers, templates, or any other processing liquid is desirable.

Recently, evaporation-induced self-assembly has been introduced as a promising strategy for the fabrication of supraparticles. Supraparticles are prepared by evaporation of sessile dispersion droplets on superhydrophobic surfaces. ${ }^{21,22}$ On simple hydrophobic surfaces, a deposited dispersion droplet will have the shape of a spherical cap. The contact line will be mostly pinned during evaporation. Pinning leads to contact angles below $90^{\circ}$ and to a higher evaporation rate of water near the contact line. As a result, liquid flows from the center of the droplet toward the contact line. This flow pattern inside the droplet leads to the formation of a ring- or doughnut-like structure of the final deposit. ${ }^{23-25}$ On superhydrophobic surfaces, however, the apparent contact angle of water droplets is above $150^{\circ}$, leading to an almost spherical droplet shape with small contact area between the droplet and substrate. As a consequence, the evaporation of water is isotropic, ensuring that the droplet will maintain a spherical morphology during the evaporation process, since water molecules can also evaporate into the porous structure of the superhydrophobic substrate. This symmetric evaporation leads to an almost spherical shape of the supraparticle. In addition, it avoids temperature-induced Marangoni flow in the evaporating droplet. $^{26}$ As the evaporation process could be easily controlled, Velev et al. were able to produce opalescent

Received: July 19, 2019

Accepted: December 2, 2019

Published: December 2, 2019 


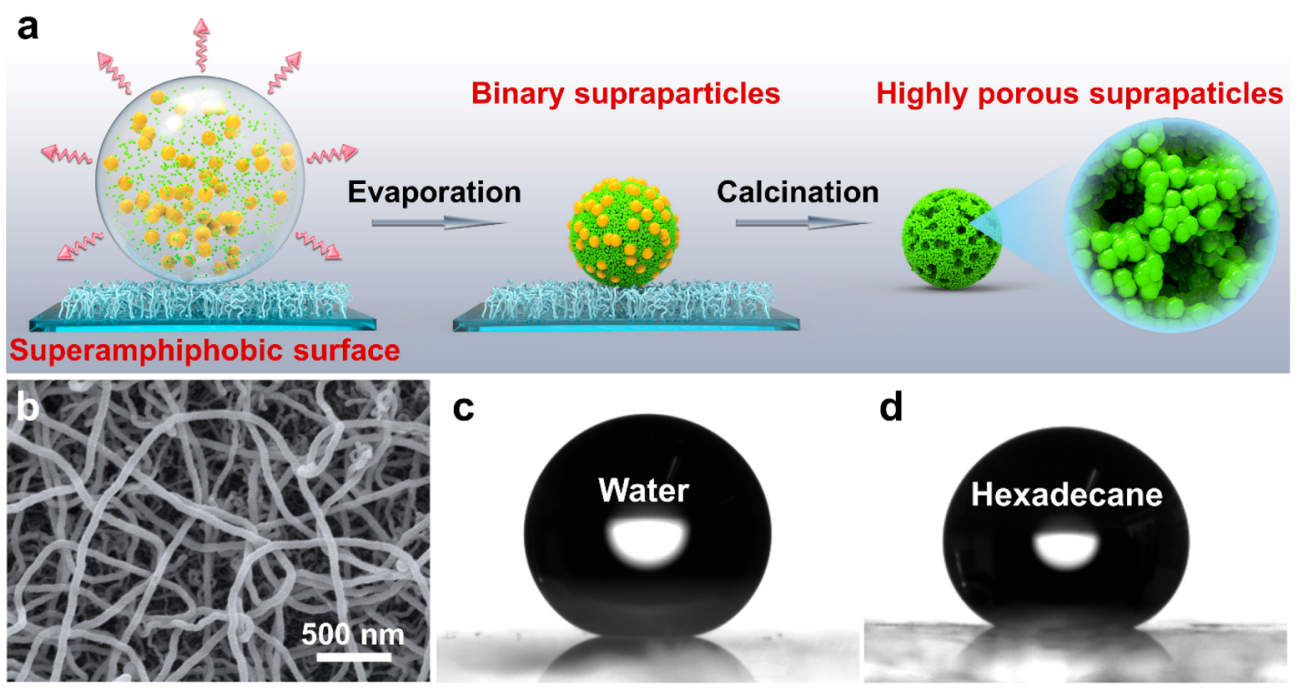

Figure 1. Surface-mediated fabrication of highly porous supraparticles. (a) Schematic illustration of porous supraparticle formation mediated by droplet evaporation and postcalcination. (b) SEM image of the nanofilaments forming the superamphiphobic substrate. (c, d) Side view images of $5 \mu \mathrm{L}$ water and hexadecane droplets on the surface.

supraparticles by forming colloidal crystals inside. ${ }^{21,27}$ Colloidal crystals are formed when nanoparticles repel each other even at a very high nanoparticle density in the later stage of drying. In contrast, irregular porous packings are favored when particles are not as stably dispersed and attract each other at some stage. ${ }^{22,28-33}$

A limitation of superhydrophobic surfaces is the restriction to use aqueous electrolyte solutions. Nonpolar liquids or surfactant solutions cannot remain in the Cassie state and impale into the structures. Furthermore, the supraparticles are sometimes not easy to release from the substrate.

Superamphiphobic surfaces overcome these limitations for supraparticle fabrication, since they repel not only water but also nonpolar liquids, surfactant, or protein solutions. Droplets on such surfaces have high contact angle $\left(\mathrm{CA}>150^{\circ}\right)$ and roll off easily (tilting angle $<10^{\circ}$ ), while the interfacial area between liquid and solid is extremely small $\left(\ll V^{2 / 3}\right) .^{34-36}$ In addition, the highly porous superamphiphobic surface leads to an almost radially symmetric evaporation, like in levitated droplets. Furthermore, the release of dried supraparticles from the substrate is facilitated because their adhesion to superamphiphobic surfaces is usually lower than to superhydrophobic surfaces. $^{36}$

Preparation of supraparticles on superamphiphobic surfaces not only avoids the expensive purification from a continuous aqueous phase and the migration and aging effects resulting from slow phase separation between particles and stabilizers, but also facilitates producing supraparticles with various sizes, compositions, and architectures by simple alternations of particle concentrations without consuming additional chemicals and energy. Porosity is a critical parameter for supraparticles, which has a great influence on the performance in practical applications, such as heterogeneous catalysis, absorber materials, and drug carriers. ${ }^{5-7}$ For many applications, one needs highly porous supraparticles to facilitate diffusion of analytes or reactants. Porosity can be increased by allowing the dispersed particles to aggregate partially. If the nanoparticles attract each other in the later stage of the evaporation, they tend to form a more porous structure rather than forming a dense packing. Porosity achieved in this way is, however, limited: during the last stage of evaporation, strong compressive capillary forces act on the nanoparticle aggregates, leading to densification of loose agglomerates.

Herein, we propose a method to increase the porosity of supraparticles and circumvent the limit set by capillary compression. We prepared $\mathrm{TiO}_{2}$ supraparticles with hierarchical porosity by first constructing $\mathrm{TiO}_{2}-$ polystyrene (PS) binary supraparticles on superamphiphobic surfaces and then removing the PS phase by calcination. By regulating the concentration and droplet volume of the mixed particle dispersions, the size of the spherical $\mathrm{TiO}_{2}$ supraparticles could be controlled. The porosity of superparticles is related to the volumetric ratio of $\mathrm{TiO}_{2}$ to PS. We demonstrate that the hierarchical porous structures of the $\mathrm{TiO}_{2}$ supraparticles enhance photocatalytic performance in degrading rhodamine $\mathrm{B}(\mathrm{RhB})$. Our approach for regulating the inner structure of supraparticles will allow optimizing them for specific applications.

\section{RESULTS AND DISCUSSION}

Fabrication of Porous Supraparticles. Highly porous supraparticles were fabricated by first depositing a droplet of a binary nanoparticle suspension on a superamphiphobic surface (Figure 1a). While water evaporates and the volume of the droplet decreases, the confinement leads to concentration of nanoparticles inside the droplet. The droplets we use were nearly spherical at the beginning because their radius $r \approx 770$ $\mu \mathrm{m}$ was lower than the capillary constant of $\kappa=2.7 \mathrm{~mm}$. During the evaporation, the scaled radius $r / \kappa$ decreases further, leading to an even more precise spherical shape. A solid binary supraparticle with spherical shape is formed. Then a calcination process was applied to remove the polymer components, forming supraparticles with highly porous structures. The evaporation was conducted on nanofilamentbased superamphiphobic surfaces, which were prepared by hydrolysis of silane (Figure $1 \mathrm{~b}$ ). ${ }^{37,38}$ The obtained superamphiphobic surface exhibits good liquid repellent properties with roll-off angles for water and hexadecane droplets $(V=5$ $\mu \mathrm{L}$ ) of $4^{\circ}$ and $8^{\circ}$, leading to a highly spherical-shaped droplet (Figure 1c,d). Such liquid repellency ensures the formation of nearly spherical droplets of nanoparticle suspension. 


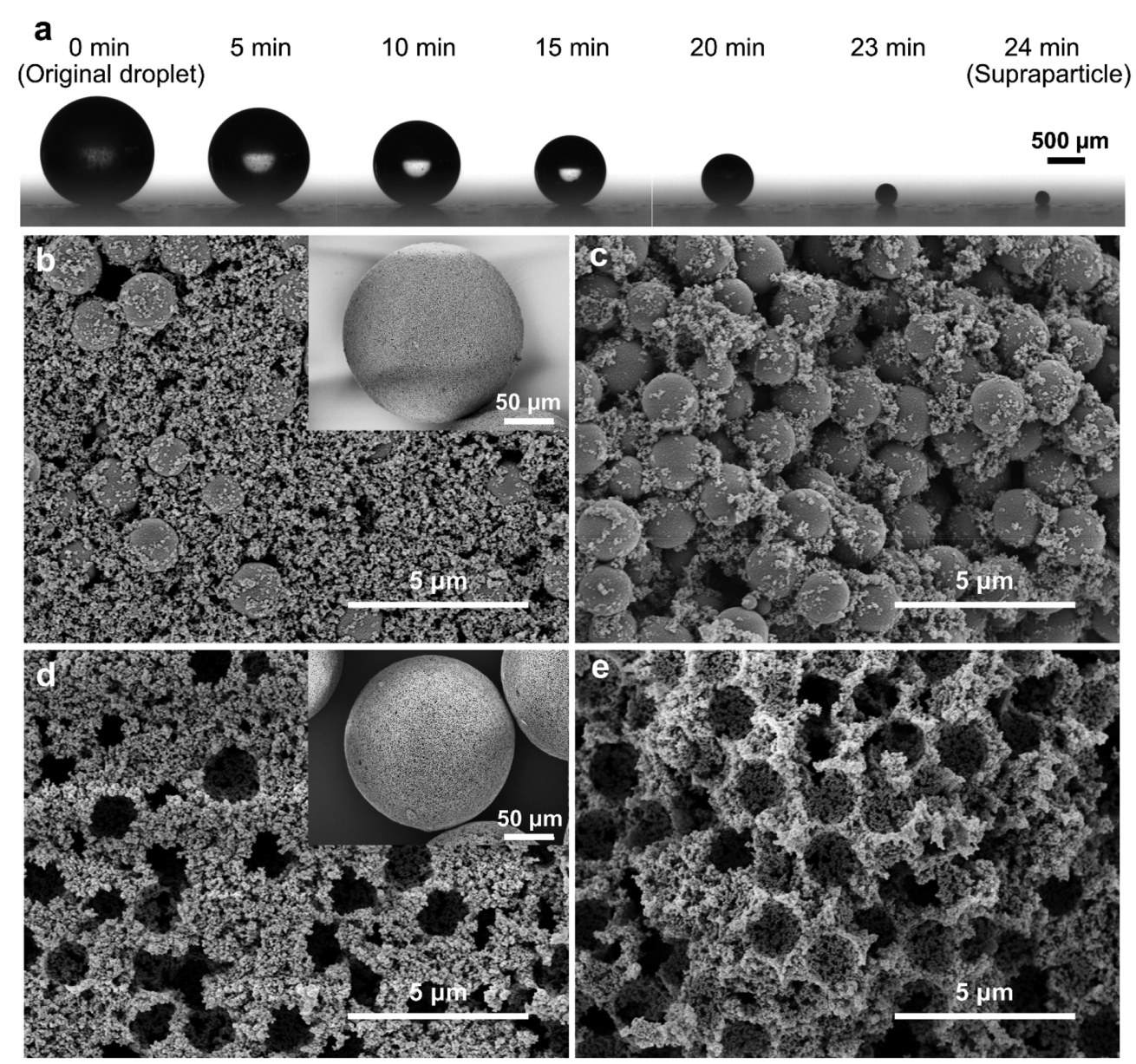

Figure 2. Supraparticles obtained after evaporation $\left(22{ }^{\circ} \mathrm{C}\right.$ at $40 \%$ relative humidity, the volume ratio of $\mathrm{TiO}_{2}$ to $\mathrm{PS}$ is $\left.1: 5\right)$ and calcination $\left(500{ }^{\circ} \mathrm{C}\right)$. (a) Evaporation of a binary colloidal dispersion droplet on a superamphiphobic surface. SEM images of the surface (b) and the inner part (c) of $\mathrm{TiO}_{2}-\mathrm{PS}$ binary supraparticles obtained after evaporation. Inset in (b) shows the whole binary supraparticle. (d, e) SEM images of the surface (d) and the inner part (e) of highly porous $\mathrm{TiO}_{2}$ supraparticles achieved after calcination. Inset in (d) shows the whole porous supraparticle.

The change in droplet shape during the evaporation process was tracked with a side view camera (IDS uEye USB camera). After depositing $2 \mu \mathrm{L}$ of $\mathrm{TiO}_{2}-\mathrm{PS}$ binary mixture ( $0.1 \mathrm{vol} \%$ of nanoparticles, volume ratio of $\mathrm{TiO}_{2}$ to $\mathrm{PS}$ is $\left.1: 5\right)$ onto the superamphiphobic surface, it takes about $24 \mathrm{~min}$ to evaporate the water $\left(22{ }^{\circ} \mathrm{C}\right.$ at $40 \%$ relative humidity, Figure $\left.2 \mathrm{a}\right)$. The suspension evaporated at a constant contact angle without contact line pinning until the end of the process. The droplet as well as the finally obtained supraparticle had a sphere-like shape, in agreement with what has been observed before. ${ }^{36,39}$ Picknett and Bexon calculated the evaporation rate of water droplets in still air, while assuming that diffusion of water molecules in air is rate-limiting. ${ }^{40}$ They showed that the volume $V^{2 / 3}$ of a sessile droplet evaporating at a constant contact angle decreases linearly with time as

$$
V^{2 / 3}=V_{0}^{2 / 3}-\alpha t
$$

Here, $V_{0}$ is the initial volume of the droplet and $\alpha$ is the evaporation speed. In our experiment, a linear decrease of $V^{2 / 3}$ was observed for both nanoparticle suspension and pure water droplets (Figure S1). The evaporation speed in the presence of nanoparticles in the droplet was similar $\left(\alpha=972 \pm 10 \mu \mathrm{m}^{2} / \mathrm{s}\right)$ to that of a pure water droplet $\left(\alpha=905 \pm 8 \mu \mathrm{m}^{2} / \mathrm{s}\right)$ evaporating under the same conditions. This similar evapo- ration speed indicates that no significant accumulating of nanoparticles at the interface occurs.

SEM images (Figure $2 \mathrm{~b}$ inset) confirm the spherical morphology of the obtained supraparticles. Small $\mathrm{TiO}_{2}$ and large PS nanoparticles are randomly distributed on the surface (Figures $2 \mathrm{~b}$ and $\mathrm{S} 2 \mathrm{a}$ ). This is due to the size and shape polydispersity of the $\mathrm{TiO}_{2}$ nanoparticles, which prevent the formation of a crystalline-like structure. To further characterize the distribution of building blocks in the microsphere, we cut the binary supraparticles in half (with a WEDO leather knife) and imaged the internal structure with SEM. Both colloids are homogeneously distributed inside the supraparticle without a large degree of segregation (Figures $2 c$ and S2b).

After removing the PS phase by calcination, a highly porous superstructure was formed (Figure $2 \mathrm{~d}, \mathrm{e}$ ). The retained $\mathrm{TiO}_{2}$ supraparticles maintained the spherical morphology and their size even after removing about $83 \%$ (vol \%) solid of the binary supraparticles (Figure $2 \mathrm{~d}$ inset). Randomly distributed macropores are formed on the surface of the supraparticle after removing PS (Figures $2 \mathrm{~d}$ and $\mathrm{S} 2 \mathrm{c}$ ). By cutting the obtained $\mathrm{TiO}_{2}$ supraparticles in half the homogeneously distributed macropores left by the PS particles are visible (Figures $2 \mathrm{e}$ and S2d). The macropores inside supraparticles are mostly interconnected to each other especially for the case of higher PS content (Figure S3). This interconnectivity is essential for 


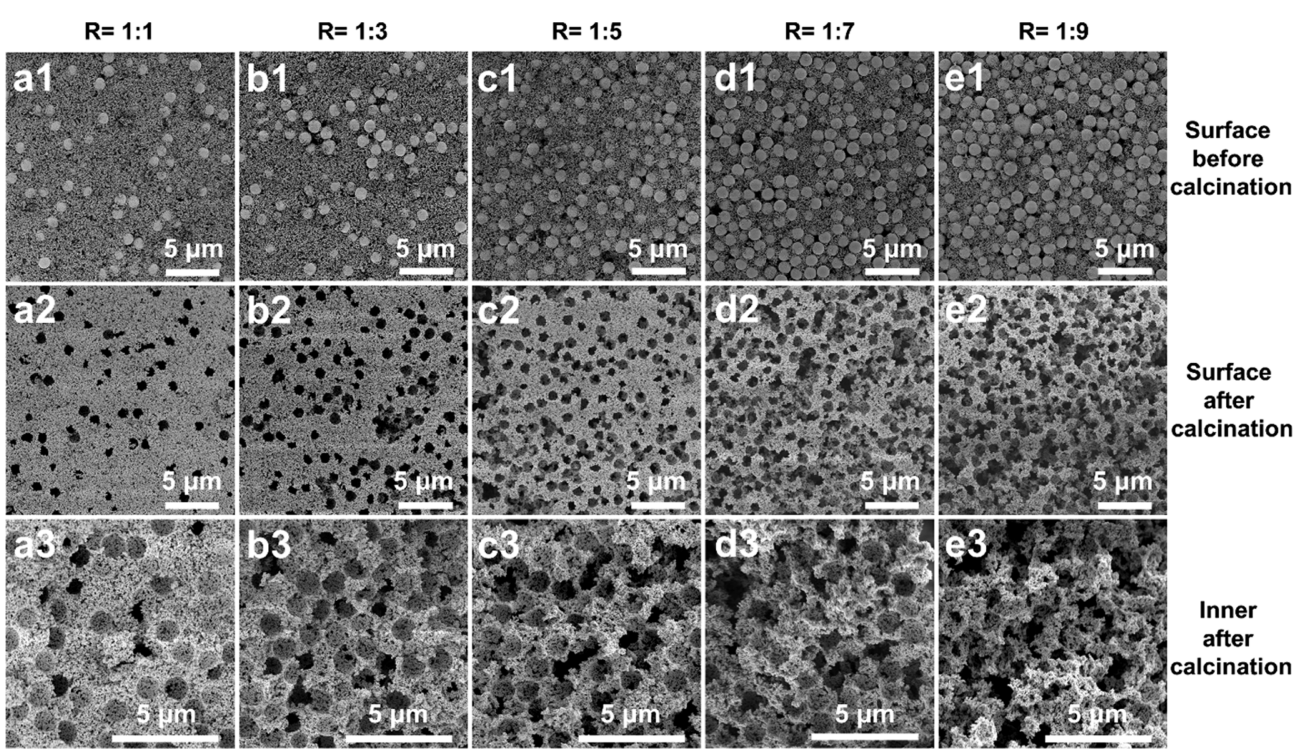

Figure 3. SEM images for the surface of binary supraparticles (1), the porous surface (2) and inner structure (3) after calcination of supraparticles. The volume ratios of $\mathrm{TiO}_{2}$ to PS equal 1:1 (a1, a2, a3), 1:3 (b1, b2, b3), 1:5 (c1, c2, c3), 1:7 (d1, d2, d3), and 1:9 (e1, e2, e3), respectively; the diameter of PS particles was about $1.25 \mu \mathrm{m}$.

applications to allow reactants to diffuse into and out of the supraparticles.

Control of the Structure of Porous Supraparticles. The final size of supraparticles can be precisely controlled by the initial droplet volume and the concentration of the components in suspension. First, we evaporated $2 \mu \mathrm{L}$ of droplets with different volume contents of nanoparticles $(0.1 \%$, $0.2 \%, 0.3 \%, 0.4 \%, 0.5 \%$, and $1 \%)$. Second, we prepared supraparticles using the same volume ratio $(0.1 \%)$ but with different droplet volumes $(0.3,0.5,1,2,5,10,40$, and $100 \mu \mathrm{L})$. The diameter of supraparticles prepared ranged from 70 to 900 $\mu \mathrm{m}$ (Figures S4 and S5). Even larger particles can in principle be prepared. However, when the diameter of the droplet approaches the capillary length $(\gamma / g \rho)^{1 / 2}$, the droplets are deformed to an oblate shape by gravity (Figure S6). Here, $\gamma$ and $\rho$ are the surface tension and density of the suspension and $g=9.81 \mathrm{~m} / \mathrm{s}^{2}$ is the standard acceleration of free fall.

The porosity of supraparticles can be adjusted in two ways: macro-pore size and volume ratio of the inorganic phase. The macro-pore size is adjustable by controlling the diameter of PS nanoparticles. As shown in Figure S7, interconnected pores could be achieved by reducing the diameter of PS particles from $1.25 \mu \mathrm{m}$ to $572 \mathrm{~nm}$ (Figure $\mathrm{S} 7 \mathrm{a}-\mathrm{c}$ ) and $270 \mathrm{~nm}$ (Figure S7d-f) and keeping the volume ratio of $\mathrm{TiO}_{2}$ to $\mathrm{PS}$ at 1:5. Macropores are still formed on the surface and the inner part. The pore size agreed with the PS nanoparticle size used in each case.

We also modulated the porosity of porous supraparticles by regulating the volume ratio of $\mathrm{TiO}_{2}$ to $\mathrm{PS}$ in nanoparticle suspension. The volume ratio $(R)$ was set to $1: 1,1: 3,1: 5,1: 7$, and 1:9. By SEM (Figure 3) we observed that the number and density of macropores correlate with $R$. Likewise, the density of pores inside the porous supraparticles also increased. The interlayer of $\mathrm{TiO}_{2}$ between macropores becomes thinner and thinner with increasing $R$. Without PS particles, mesopores are formed by the interstitial space between the $\mathrm{TiO}_{2}$ nanoparticles. Since $\mathrm{TiO}_{2}$ nanoparticles tend to attract each other at short distance, they do not form a crystalline close packing but a more porous packing. When adding PS particles, macropores are formed. Interconnection of macropores will occur if neighboring PS particles contact with each other before the calcination process. Such contacts will become more likely when the $R$ of $\mathrm{TiO}_{2}$ to PS in the nanoparticle suspension decreases. Table S1 shows the volume fraction of PS particles in the final supraparticles as derived from supraparticle size and added amount of PS templates. With $R$ decreasing, PS particles in the binary supraparticles reach but do not exceed a volume fraction of $49.4 \%$. This volume fraction corresponds to the minimum density of a jammed packing, indicating that PS particles form such a jammed configuration during the drying process. In such a minimal jammed packing configuration, each particle should on average contact seven immediate neighbors, resulting in a corresponding number of interconnections between macropores in the final porous supraparticles. ${ }^{41,42}$ The lowest volume ratio of $\mathrm{TiO}_{2}$ to PS we could reach was 1:9. This means even after removing $90 \%$ of the solid phase in the binary supraparticles, the remaining $\mathrm{TiO}_{2}$ still preserved the spherical morphology of the supraparticles. The porosity of the final porous supraparticles obtained in each case was calculated based on the initial $\mathrm{TiO}_{2}$ volume in the droplet and the size of the supraparticle. Pure $\mathrm{TiO}_{2}(R=1: 0)$ supraparticles have a porosity of $66 \%$. With increasing of the PS volume ratio, the porosity gradually increased to $74.8 \%, 83.4 \%, 89.5 \%, 91.6 \%$, and $92.1 \%$, respectively (Figure S8). The porosity of the supraparticles would be hard to measure directly, since typical experimental methods such as gas sorption/desorption would fail for the combination of micro- and macropores. However, since only the inorganic phase remains after the calcination process, the porosity of supraparticles can simply be calculated based on the $\mathrm{TiO}_{2}$ volume in the original droplet and the diameter of the final $\mathrm{TiO}_{2}$ supraparticles. These results demonstrate that the structural parameters of the porous supraparticles, such as size, macropore size, and porosity, can be easily determined by defining the evaporation conditions. Therefore, preparation of highly porous supraparticles can be carried out in a finely controllable manner.

Binary superlattice thin films could be seen as an alternative approach to create highly porous materials with a comparable 

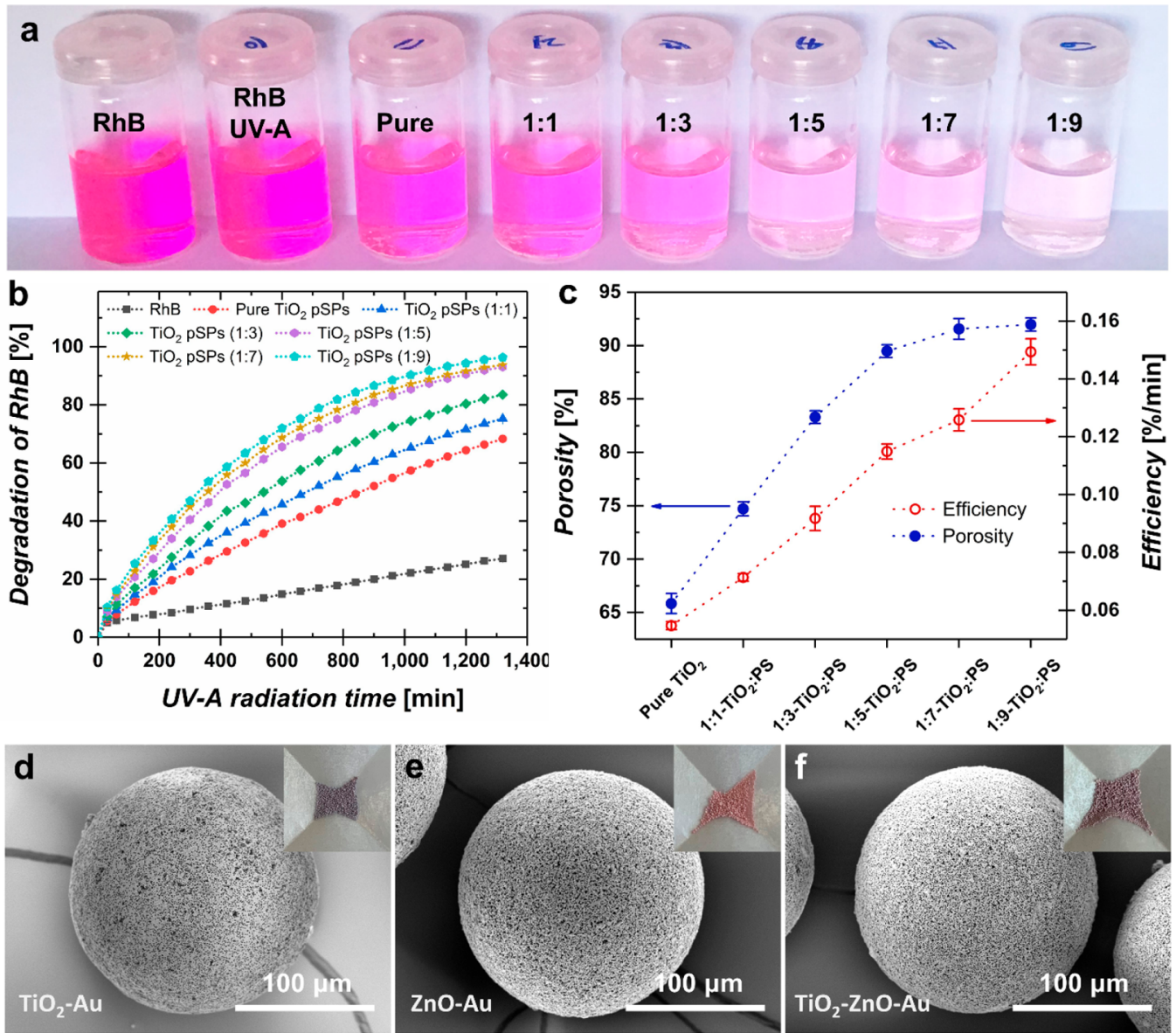

Figure 4. Porosity-dependent photocatalytic efficiency enhancement and supraparticles prepared from different materials. (a) Optical image of rhodamine B (RhB)/supraparticle solutions after exposure to UV-A for $22 \mathrm{~h}$. (b) Relationship between degradation of RhB and irridation time for supraparticles with different porosity. (c) Relationship between photocatalytic efficiency and porosity. (d, e) SEM images of binary $\mathrm{TiO}_{2}-\mathrm{Au}$ and $\mathrm{ZnO}-\mathrm{Au}$ porous supraparticles made from $\mathrm{TiO}_{2} / \mathrm{Au} / \mathrm{PS}$ (40:1:200) and $\mathrm{ZnO} / \mathrm{Au} / \mathrm{PS}$ (40:1:200) ternary suspensions. (F) SEM image of a ternary $\mathrm{TiO}_{2}-\mathrm{ZnO}-\mathrm{Au}$ porous supraparticle fabricated from a $\mathrm{TiO}_{2} / \mathrm{ZnO} / \mathrm{Au} / \mathrm{PS}(20: 20: 1: 200)$ quaternary suspension. Insets are optical images of the hybrid supraparticles.

internal microstructure. By using larger PS particles for the formation of the lattice structure and filling of the voids with $\mathrm{TiO}_{2}$ nanoparticles, one could create inverse opals of $\mathrm{TiO}_{2}$ after calcination. ${ }^{43,44}$ In this case, the achievable porosity would even be higher due to the closer packing of the PS spheres. Tuning of the porosity in this case would be possible via variation of the size ratios of $\mathrm{PS}$ and $\mathrm{TiO}_{2}$ particles. Therefore, one would expect that the catalytic activity of both systems should in principle be similar. The main advantages of the supraparticles are (1) the simple way of fabrication (just placing a droplet and letting it evaporate), (2) tuning of porosity is more simple (no need for different PS particle sizes but just varying concentration), and (3) the final product comes without supporting substrate. This offers more flexibility in handling and application scenarios. The supraparticles in dispersion are highly mobile and can be easily transferred, concentrated, or diluted as required. The size of the spherical supraparticles can range from a few tens of micrometers to a few millimeters. Therefore, they can readily be adopted in existing application systems (such as drug carriers and catalysts in reaction vessels).

Mechanical Properties. To evaluate the potential benefit of the highly porous supraparticles for practical applications, the mechanical stability and photocatalytic activity were further investigated. The fracture force of single supraparticles with different porosity was measured with a home-built forcesensing system, which allowed particle compression between two parallel glass plates equipped with a force sensor and a stepper motor. ${ }^{45}$ For the pure mesoporous $\mathrm{TiO}_{2}$ supraparticles without macropores, the fracture force for a single particle was $\sim 175 \mathrm{mN}$ (Figure S8). With the introduction of macropores, the mechanical stability was significantly reduced. With increasing porosity, the fracture force further decreased. For supraparticles with a porosity higher than $85 \%$, the fracture force decreased to about $4-5 \mathrm{mN}$. Even though these highly porous particles are more fragile, even for the supraparticles with the largest porosity (92\%), the fracture force is still about 600000 times larger than the gravitational force (Figure S9). This means that a densely packed bed of such particles could reach a height of $76 \mathrm{~m}$ before the lowermost particles would start to break. Therefore, even the supraparticles with the largest porosity prepared by our method are stable enough for practical use.

Photocatalytic Efficiency. $\mathrm{TiO}_{2}$ is commonly used as photocatalyst for degradation of organic dyes, splitting of water, decontamination, photosynthesis, etc. ${ }^{46-49}$ Improvement in its photocatalytic activity without using chemical modification is of great importance. The photodegradation performance of the $\mathrm{TiO}_{2}$ supraparticles with different porosities was investigated to evaluate the effect of macropores. 
Rhodamine B, a typical organic dye, was chosen as a model compound for photocatalytic degradation. The process was conducted by irradiation with UV-A light (power: $0.3 \pm 0.01$ $\mathrm{mW} / \mathrm{cm}^{2}$ ). As shown in Figure $4 \mathrm{a}$, after $22 \mathrm{~h}$ of irradiation, the organic dye in solution containing the largest porosity $\mathrm{TiO}_{2}$ supraparticles is nearly completely degraded ( $\sim 97 \%, 72 \%$ of the degradation was contributed by $\mathrm{TiO}_{2}$ supraparticles). The photocatalytic activity of the porous supraparticles increased with increasing porosity (Figure $4 \mathrm{~b}, \mathrm{c}$ ). The photocatalytic activity of supraparticles with the largest porosity reached about 2.7 times of that of mesoporous supraparticles without macropores. We attribute the enhancement of photocatalytic activity to the existence of macropores, making it much easier for the organic dye to diffuse into supraparticles, increasing the effectively available surface area for photocatalytic reaction. For catalytic reactions, which do not depend on light, the effect is probably even more pronounced. For photocatalysis, the inner part of the supraparticles is not effective because light is absorbed in the outer shell. These results show that the introduction of macropores can improve the catalytic property of the supraparticles. Our method is therefore a promising approach for the production of highly porous supraparticles with enhanced properties in an environmentally friendly manner.

As the approach presented here is mainly controlled by the evaporation of droplets on superamphiphobic surfaces, our method can easily be adopted to fabricate highly porous supraparticles from other materials in an environmental friendly manner. Figure $4 \mathrm{~d}-\mathrm{f}$ shows the highly porous binary and ternary suprapaticles $\left(\mathrm{TiO}_{2}-\mathrm{Au}, \mathrm{ZnO}-\mathrm{Au}, \mathrm{TiO}_{2}-\mathrm{ZnO}\right.$ $\mathrm{Au}$ ) fabricated by mixing two functional materials or adding noble metal nanoparticles in the droplet. Again we maintain spherical morphology and evenly distributed macropores spanning a network from the surface to the inner core. Moreover, other supraparticles, e.g., $\mathrm{ZnO}, \mathrm{SiO}_{2}$, and $\mathrm{TiO}_{2}-$ $\mathrm{ZnO}$, can also be obtained by using the same method (Figure S10). These results confirmed the possibility of our approach for integrating multiple functions into a single supraparticle for optimized applications.

\section{CONCLUSIONS}

In conclusion, we fabricate highly porous surpraparticles based on evaporation of droplets of suspensions on superamphiphobic surfaces. Taking advantage of the liquid repellency of the superamphiphobic surface, we suppress contact line pinning during the evaporation, leading to the formation of spherical multicomponent supraparticles that can be easily released from the surface. To increase the porosity of the supraparticles, we add sacrificial polymer nanoparticles. After formation of supraparticles these polymer nanoparticles are burned away to create interconnected pores. The structures of the obtained porous supraparticles (particle size, pore size, porosity, and component distribution) are finely adjustable by regulating droplet volume, dispersion concentration, choice of primary particles, and sacrificial particles. The flexibility of our approach has the potential to expand applications of supraparticles in research areas such as absorber materials in chromatography, heterogeneous catalysts, and drug carriers.

\section{EXPERIMENTAL METHODS}

Materials. Methyltrichlorosilane (TCMS, 99\%), $\mathrm{TiO}_{2}$ nanoparticles (P25, mixture of anatase and rutile), and hexadecane (reagentPlus, 99\%) were purchased from Aldrich. $1 \mathrm{H}, 1 \mathrm{H}, 2 \mathrm{H}, 2 \mathrm{H}$ -
Perfluorodecyltrichlorosilane (PFDTS, 96\%) was purchased from Alfa Aesar; $n$-hexane (95\%) from Fisher Chemical. Toluene, acetone, and ethanol absolute were provided by VWR Chemicals. Ultrapure water with a resistivity of $18.2 \mathrm{M} \Omega \cdot \mathrm{cm}$ was produced using a Sartorius Arium $611 \mathrm{VF}$ water purification system. Glass slides of $26 \times 76 \mathrm{~mm}^{2}$ in size were provided by Menzel-Gläser, Germany. Polystyrene particles (negative charged, with a $-\mathrm{COOH}$ group on the surface) with diameters of $270 \mathrm{~nm}, 572 \mathrm{~nm}$, and $1.25 \mu \mathrm{m}$ were prepared using surfactant-free emulsion polymerization ${ }^{50}$ and purified by several cycles of centrifugation and redispersion in ultrapure water.

Fabrication of a Silicone Nanofilaments Based Superamphiphobic Surface. The superamphiphobic surfaces were prepared by the grow-from method. ${ }^{37,38}$ Glass slides were first cleaned with toluene, acetone, absolute ethanol under ultrasonication, and dried by nitrogen flow. Then the substrates were treated with an oxygen plasma (Diener Electronic Femto, $30 \mathrm{~W}$ for $2 \mathrm{~min}$ ). Five activated glass slides were immersed in $360 \mathrm{~mL}$ of toluene with 166 ppm water in a reaction chamber. Subsequently, $250 \mu \mathrm{L}$ of TCMS was added to initiate the growth of silicone nanofilaments, and the chamber was sealed. After $12 \mathrm{~h}$ of reaction, the silicone nanofilamentgrafted glass slides were rinsed with hexane and dried under a nitrogen flow. To achieve superamphiphobicity, the substrate is modified with $1 \mathrm{H}, 1 \mathrm{H}, 2 \mathrm{H}, 2 \mathrm{H}$-perfluorodecyltrichlorosilane. For the modification of PFDTS, the silicone nanofilaments were further activated with oxygen plasma ( $120 \mathrm{~W}$ for $2 \mathrm{~min}$ ). Then the activated substrates were immersed in a mixture of $180 \mu \mathrm{L}$ of PFDTS and 120 $\mathrm{mL}$ of hexane for $30 \mathrm{~min}$. After the modification, the substrates were rinsed with hexane and dried under nitrogen flow. The obtained nanofilament-coated glass was homogeneous over a large area, and the micropores and overhangs formed by the silicone fibers endowed the surface with its nonwettability. Water droplets possess a static contact angle over $161^{\circ}$ (Figure 1c) with a sliding angle of about $4^{\circ}$, while hexadecane droplets have a contact angle around $156^{\circ}$ (Figure 1d) with a sliding angle about $8^{\circ}$ at a volume of $5 \mu \mathrm{L}$.

Preparation and Modulation of Hierarchical Porous $\mathrm{TiO}_{2}$ Supraparticles. Hierarchical porous $\mathrm{TiO}_{2}$ supraparticles were prepared by calcination of $\mathrm{TiO}_{2} / \mathrm{PS}$ binary supraparticles that were fabricated on a superamphiphobic surface. First, $2 \mu \mathrm{L}$ of binary mixture of $\mathrm{TiO}_{2}$ and PS particles with the concentration equal to $0.1 \%$ (vol) were dropped onto a silicone nanofilament-based superamphiphobic surface with the help of an Eppendorf Research Plus pipet (equipped with epT.I.P.S. LoRetention Reloads tips). Then water evaporated at $22{ }^{\circ} \mathrm{C}$ and relative humidity (RH) was equal to $40 \%$. The binary $\mathrm{TiO}_{2} / \mathrm{PS}$ supraparticles formed after evaporation were released by slightly inclining and shaking. Supraparticles were collected on a weighing paper and then transferred into a bottle vial. The binary supraparticles are stable for collection and handling without attrition. However, when immersing them in water, they tend to disintegrate, since the particles are hydrophilic and there are no strong interactions between $\mathrm{TiO}_{2}$ and PS. In some cases, trace amounts of the nanofilaments were left behind at the supraparticle surface (Figure S11) since the nanofilaments may still have a few hydrophilic points that can pin the contact line. The binary $\mathrm{TiO}_{2} / \mathrm{PS}$ supraparticles were put into a muffle furnace and calcinated at $500{ }^{\circ} \mathrm{C}$ for $3 \mathrm{~h}$ to remove the PS and form pure $\mathrm{TiO}_{2}$ supraparticles with hierarchical porosity. The final $\mathrm{TiO}_{2}$ supraparticles showed improved stability and did not disintegrate when immersed in water. The final size of supraparticles could be adjusted by the volume content of nanoparticles (range $0.1-1 \%$ ) and the initial volumes $(0.3-100 \mu \mathrm{L}$ ). Meanwhile, the porosity and the size of macropores can also be regulated with the volume ratio of $\mathrm{TiO}_{2}$ to $\mathrm{PS}$ and the size of template PS. It is worth noting that the transformation temperature of anatase to rutile is around $500-800{ }^{\circ} \mathrm{C}$. Choosing $500{ }^{\circ} \mathrm{C}$ for calcination did not cause any detectable crystal transformation, while complete removal of the organic component is ensured (Figure S12).

Photocatalytic Activity. To measure the photocatalytic activity of $\mathrm{TiO}_{2}$ supraparticles, $2 \mathrm{mg}$ of $\mathrm{TiO}_{2}$ SPs with different porosities were placed into $8 \mathrm{~mL}$ vials containing a $\mathrm{RhB}$ solution $(10 \mu \mathrm{g} / \mathrm{mL}, 5$ $\mathrm{mL}$ ) separately. The supraparticles formed a monolayer on the bottom and did not shield each other. Then the mixtures were 
radiated from the bottom side with a UV-A light (UV source: LQ400 , Dr. Gröbel UV-Elektronik $\mathrm{GmbH}$ ) for a certain time at a power of $0.3 \pm 0.01 \mathrm{~mW} / \mathrm{cm}^{2}$. The photodegradation process was conducted without stirring. As a control group, $5 \mathrm{~mL}$ of $\mathrm{RhB}$ solution without $\mathrm{TiO}_{2}$ SPs and $5 \mathrm{~mL}$ of $\mathrm{RhB}$ solution with $2 \mathrm{mg}$ of pure $\mathrm{TiO}_{2} \mathrm{SPs}$ without macroporous were irradiated with the UV-A light under the same conditions.

Characterization. The morphology of the silicone nanofilaments and supraparticles was imaged by scanning electron microscopy (low voltage LEO 1530 Gemini, Germany). The samples were sputtercoated with a $5 \mathrm{~nm}$ layer of Pt using a BalTec MED 020 modular high-vacuum coating system prior to avoid charging. Static and sliding angles of $5 \mu \mathrm{L}$ water and hexadecane droplets on the nanofilamentbased superamphiphobic surface were measured with a goniometer, Dataphysics OCA35 (Data Physics Instruments GmbH, Germany). UV-vis adsorption spectra were taken from a PerkinElmer Lambda $25 \mathrm{UV}$-vis spectrometer with Suprasil QS $1 \mathrm{~mm}$ cuvettes. The water concentration in toluene was evaluated using a Karl Fischer coulometer (Mettler Toledo C20 Compact KF coulometer). Optical micrographs were taken by an optical microscope (Carl Zeiss Axiotech Vario 100HD). TEM images of $\mathrm{TiO}_{2}$ nanoparticles with and without calcination were taken by transmission electron microscopy (JEOL JEM-1400). Powder XRD measurement was performed on a Bruker D8 ADVANCE Twin X-ray diffractometer with $\mathrm{Cu} \mathrm{K} \alpha$ radiation.

\section{ASSOCIATED CONTENT}

\section{S Supporting Information}

The Supporting Information is available free of charge at https://pubs.acs.org/doi/10.1021/acsnano.9b05673.

Supplementary SEM and optical microscope measurements of supraparticles; evaporation speed of pure water and colloidal suspension; mechanical stability of porous supraparticles; XRD patterns and TEM images of $\mathrm{TiO}_{2}$ (P25) nanoparticles with and without calcination (PDF)

\section{AUTHOR INFORMATION}

\section{Corresponding Author}

*Tel: +49 6131379114. E-mail: kappl@mpip-mainz.mpg.de.

\section{ORCID}

Wendong Liu: 0000-0001-7297-8591

Michael Kappl: 0000-0001-7335-1707

Hans-Jürgen Butt: 0000-0001-5391-2618

\section{Author Contributions}

W.L., M.K., and H.-J.B. conceived and designed the experiments. W.L. performed the experiments and characterizations. W.L., M.K., and H.-J.B. cowrote the paper. All authors discussed the results and commented on the manuscript.

\section{Notes}

The authors declare no competing financial interest.

\section{ACKNOWLEDGMENTS}

This work was supported by the Max Planck Center for Complex Fluid Dynamics and the ERC advanced grant 340391 SUPRO (W.L., H.-J.B.). W.L. thanks Prof. Dr. Sanghyuk Wooh and Prof. Dr. Werner Steffen for helpful discussions. We also gratefully acknowledge Gabriele Schäfer for synthesizing thepolystyrene nanoparticles and Prof. Dr. Markus Mezger for carrying out the XRD analysis.

\section{REFERENCES}

(1) Mattos, B. D.; Greca, L. G.; Tardy, B. L.; Magalhães, W. L. E.; Rojas, O. J. Green Formation of Robust Supraparticles for Cargo
Protection and Hazards Control in Natural Environments. Small 2018, 14, 1801256.

(2) Wintzheimer, S.; Granath, T.; Oppmann, M.; Kister, T.; Thai, T.; Kraus, T.; Vogel, N.; Mandel, K. Supraparticles: Functionality from Uniform Structural Motifs. ACS Nano 2018, 12, 5093-5120.

(3) Luo, D.; Yan, C.; Wang, T. Interparticle Forces Underlying Nanoparticle Self-Assemblies. Small 2015, 11, 5984-6008.

(4) Zhang, R.; Elzatahry, A. A.; Al-Deyab, S. S.; Zhao, D. Mesoporous Titania: From Synthesis to Application. Nano Today 2012, 7, 344-366.

(5) Li, X.; Visaveliya, N.; Hafermann, L.; Gross, G. A.; Knauer, A.; Köhler, J. M. Hierarchically Structured Particles for Micro Flow Catalysis. Chem. Eng. J. 2017, 326, 1058-1065.

(6) Park, J.-S.; Kim, S.-H.; Makgkiriadou, S.; Choi, T. M.; Kim, Y.-S.; Manharan, V. N. Full-Spectrum Photonic Pigments with NonIridescent Structural Colors through Colloidal Assembly. Angew. Chem., Int. Ed. 2014, 53, 2899-2903.

(7) Zhao, Y.; Zheng, Y.; Shang, L.; Wang, J.; Xie, Z.; Gu, Z. Microfluidic Synthesis of Barcode Particles for Multiplex Assays. Small 2015, 11, 151-174.

(8) Koo, H.-J.; Kim, Y. J.; Lee, Y. H.; Lee, W. I.; Kim, K.; Park, N.-G. Nano-Embossed Hollow Spherical $\mathrm{TiO}_{2}$ as Bifunctional Material for High-Efficiency Dye-Sensitized Solar Cells. Adv. Mater. 2008, 20, 195-199.

(9) Li, X.; Gu, M.; Hu, S.; Kennard, R.; Yan, P.; Chen, X.; Wang, C.; Sailor, M. J.; Zhang, J.-G.; Liu, J. Mesoporous Silicon Sponge as an Anti-Pulverization Structure for High-Performance Lithium-Ion Battery Anodes. Nat. Commun. 2014, 5, 4105.

(10) Wang, T.; LaMontagne, D.; Lynch, J.; Zhuang, J.; Cao, Y. C. Colloidal Superparticles from Nanoparticle Assembly. Chem. Soc. Rev. 2013, 42, 2804-2823.

(11) Deans, R.; Ilhan, F.; Rotello, V. M. Recognition-Mediated Unfolding of a Self-Assembled Polymeric Globule. Macromolecules 1999, 32, 4956-4960.

(12) Maye, M. M.; Lim, I. I. S.; Luo, J.; Rab, Z.; Rabinovich, D.; Liu, T.; Zhong, C.-J. Mediator-Template Assembly of Nanoparticles. J. Am. Chem. Soc. 2005, 127, 1519-1529.

(13) Klajn, R.; Bishop, K. J. M.; Fialkowski, M.; Paszewski, M.; Campbell, C. J.; Gray, T. P.; Grzybowski, B. A. Plastic and Moldable Metals by Self-Assembly of Sticky Nanoparticle Aggregates. Science 2007, 316, 261-264.

(14) Klajn, R.; Bishop, K. J. M.; Grzybowski, B. A. Light-Controlled Self-Assembly of Reversible and Irreversible Nanoparticle Suprastructures. Proc. Natl. Acad. Sci. U. S. A. 2007, 104, 10305-10309.

(15) Wang, D.; Xie, T.; Peng, Q.; Li, Y. $\mathrm{Ag}, \mathrm{Ag}_{2} \mathrm{~S}$, and $\mathrm{Ag}_{2} \mathrm{Se}$ Nanocrystals: Synthesis, Assembly, and Construction of Mesoporous Structures. J. Am. Chem. Soc. 2008, 130, 4016-4022.

(16) Lim, S. I.; Zhong, C.-J. Molecularly Mediated Processing and Assembly of Nanoparticles: Exploring the Interparticle Interactions and Structures. Acc. Chem. Res. 2009, 42, 798-808.

(17) Jenekhe, S. A.; Chen, X. L. Self-Assembled Aggregates of RodCoil Block Copolymers and Their Solubilization and Encapsulation of Fullerenes. Science 1998, 279, 1903-1907.

(18) Bai, F.; Wang, D.; Huo, Z.; Chen, W.; Liu, L.; Liang, X.; Chen, C.; Wang, X.; Peng, Q.; Li, Y. A Versatile Bottom-Up Assembly Approach to Colloidal Spheres from Nanocrystals. Angew. Chem., Int. Ed. 2007, 46, 6650-6653.

(19) Lu, F.; Cai, W.; Zhang, Y. ZnO Hierarchical Micro/ Nanoarchitectures: Solvothermal Synthesis and Structurally Enhanced Photocatalytic Performance. Adv. Funct. Mater. 2008, 18, 1047-1056.

(20) Han, J.; Zhang, X.; Zhou, Y.; Ning, Y.; Wu, J.; Liang, S.; Sun, H.; Zhang, H.; Yang, B. Fabrication of CdTe Nanoparticles-Based Superparticles for an Improved Detection of $\mathrm{Cu}^{2+}$ and $\mathrm{Ag}^{+}$. J. Mater. Chem. 2012, 22, 2679-2686.

(21) Rastogi, V.; Melle, S.; Calderón, O. G.; Marquez, M.; Velev, O. D. Synthesis of Light-Diffracting Assemblies from Microspheres and Nanoparticles in Droplets on a Superhydrophobic Surface. Adv. Mater. 2008, 20, 4263-4268. 
(22) Marin, Á. G.; Gelderblom, H.; Susarrey-Arce, A.; Van Houselt, A.; Lefferts, L.; Gardeniers, J. G. E.; Lohse, D.; Snoeijer, J. H. Building Microscopic Soccer Balls with Evaporating Colloidal Fakir Drops. Proc. Natl. Acad. Sci. U. S. A. 2012, 109, 16455-16458.

(23) Zhou, J.; Man, X.; Jiang, Y.; Doi, M. Structure Formation in Soft-Matter Solutions Induced by Solvent Evaporation. Adv. Mater. 2017, 29, 1703769.

(24) Sefiane, K. Patterns from Drying Drops. Adv. Colloid Interface Sci. 2014, 206, 372-381.

(25) Routh, A. F. Drying of Thin Colloidal Films. Rep. Prog. Phys. 2013, 76, 046603 .

(26) Tan, H.; Diddens, C.; Versluis, M.; Butt, H.-J.; Lohse, D.; Zhang, X. Self-Wrapping of an Ouzo Drop Induced by Evaporation on a Superamphiphobic Surface. Soft Matter 2017, 13, 2749-2759.

(27) Rastogi, V.; Garcia, A. A.; Marquez, M.; Velev, O. D. Anisotropic Particle Synthesis Inside Droplet Templates on Superhydrophobic Surfaces. Macromol. Rapid Commun. 2010, 31, 190-195.

(28) Sekido, T.; Wooh, S.; Fuchs, R.; Kappl, M.; Nakamura, Y.; Butt, H.-J.; Fujii, S. Controlling the Structure of Supraballs by $\mathrm{pH}-$ Responsive Particle Assembly. Langmuir 2017, 33, 1995-2002.

(29) Sperling, M.; Velev, O. D.; Gradzielski, M. Controlling the Shape of Evaporating Droplets by Ionic Strength: Formation of Highly Anisometric Silica Supraparticles. Angew. Chem., Int. Ed. 2014, 53, 586-590.

(30) Sperling, M.; Papadopoulos, P.; Gradzielski, M. Understanding the Formation of Anisometric Supraparticles: A Mechanistic Look Inside Droplets Drying on a Superhydrophobic Surface. Langmuir 2016, 32, 6902-6908.

(31) Lee, D.-W.; Jin, M.-H.; Lee, C.-B.; Oh, D.; Ryi, S.-K.; Park, J.S.; Bae, J.-S.; Lee, Y.-J.; Park, S.-J.; Choi, Y.-C. Facile Synthesis of Mesoporous Silica and Titania Supraparticles by a Meniscus Templating Route on a Superhydrophobic Surface and Their Application to Adsorbents. Nanoscale 2014, 6, 3483-3487.

(32) Yu, B.; Cong, H.; Yuan, H.; Liu, X.; Peng, Q.; Zhang, X.; Xu, X.; Tian, C.; Yang, R.; Yang, S. Preparation of Doughnut-Like Nanocomposite Colloidal Crystal Particles with Enhanced Light Diffraction Using Drying Self-Assembly Method. Curr. Nanosci. 2015, 11, 161-165.

(33) Zhou, J.; Yang, J.; Gu, Z.; Zhang, G.; Wei, Y.; Yao, X.; Song, Y.; Jiang, L. Controllable Fabrication of Noniridescent Microshaped Photonic Crystal Assemblies by Dynamic Three-Phase Contact Line Behaviors on Superhydrophobic Substrates. ACS Appl. Mater. Interfaces 2015, 7, 22644-22651.

(34) Chu, Z.; Seeger, S. Superamphiphobic Surfaces. Chem. Soc. Rev. 2014, 43, 2784-2798.

(35) Deng, X.; Mammen, L.; Butt, H.-J.; Vollmer, D. Candle Soot as a Template for a Transparent Robust Superamphiphobic Coating. Science 2012, 335, 67-70.

(36) Wooh, S.; Huesmann, H.; Tahir, M. N.; Paven, M.; Wichmann, K.; Vollmer, D.; Tremel, W.; Papadopoulos, P.; Butt, H.-J. Synthesis of Mesoporous Supraparticles on Superamphiphobic Surfaces. Adv. Mater. 2015, 27, 7338-7343.

(37) Zhang, J.; Seeger, S. Superoleophobic Coatings with Ultralow Sliding Angles Based on Silicone Nanofilaments. Angew. Chem., Int. Ed. 2011, 50, 6652-6656.

(38) Geyer, F.; Schönecker, C.; Butt, H.-J.; Vollmer, D. Enhancing $\mathrm{CO}_{2}$ Capture Using Robust Superomniphobic Membranes. Adv. Mater. 2017, 29, 1603524.

(39) Liu, W.; Midya, J.; Kappl, M.; Butt, H.-J.; Nikoubashman, A. Segregation in Drying Binary Colloidal Droplets. ACS Nano 2019, 13, 4972-4979.

(40) Picknett, R. G.; Bexon, R. The Evaporation of Sessile or Pendant Drops in Still Air. J. Colloid Interface Sci. 1977, 61, 336-350.

(41) Torquato, S.; Stillinger, F. H. Toward the Jamming Threshold of Sphere Packings: Tunneled Crystals. J. Appl. Phys. 2007, 102, 093511.

(42) Torquato, S. Perspective: Basic Understanding of Condensed Phases of Matter via Packing Models. J. Chem. Phys. 2018, 149, 020901.
(43) Wang, J.; Li, Q.; Knoll, W.; Jonas, U. Preparation of Multilayered Trimodal Colloid Crystals and Binary Inverse Opals. J. Am. Chem. Soc. 2006, 128, 15606-15607.

(44) Kwak, E. S.; Lee, W.; Park, N.-G.; Kim, J.; Lee, H. Inverse-Opal Electrodes: Compact Inverse-Opal Electrode Using Non-Aggregated $\mathrm{TiO}_{2}$ Nanoparticles for Dye-Sensitized Solar Cells. Adv. Funct. Mater. 2009, 19, 1093-1099.

(45) Azizian, S.; Fujii, S.; Kasahara, M.; Butt, H.-J.; Kappl, M. Effect of Particle Morphology on Mechanical Properties of Liquid Marbles. Adv. Powder Technol. 2019, 30, 330-335.

(46) Lee, S.-Y.; Park, S.-J. $\mathrm{TiO}_{2}$ Photocatalyst for Water Treatment Applications. J. Ind. Eng. Chem. 2013, 19, 1761-1769.

(47) Lan, Y.; Lu, Y.; Ren, Z. Mini Review on Photocatalysis of Titanium Dioxide Nanoparticles and Their Solar Applications. Nano Energy 2013, 2, 1031-1045.

(48) Shanker, U.; Rani, M.; Jassal, V. Degradation of Hazardous Organic Dyes in Water by Nanomaterials. Environ. Chem. Lett. 2017, $15,623-642$.

(49) Schneider, J.; Matsuoka, M.; Takeuchi, M.; Zhang, J.; Horiuchi, Y.; Anpo, M.; Bahnemann, D. W. Understanding $\mathrm{TiO}_{2}$ Photocatalysis: Mechanisms and Materials. Chem. Rev. 2014, 114, 9919-9986.

(50) Shouldice, G. T. D.; Vandezande, G. A.; Rudin, A. Practical Aspects of the Emulsifier-Free Emulsion Polymerization of Styrene. Eur. Polym. J. 1994, 30, 179-183. 